\title{
Targeted panel sequencing in adult patients with left ventricular non-compaction reveals a large genetic heterogeneity
}

\begin{tabular}{|c|c|}
\hline Journal: & Clinical Genetics \\
\hline Manuscript ID & CGE-00461-2018.R1 \\
\hline Manuscript Type: & Original Article \\
\hline Date Submitted by the Author: & $\mathrm{n} / \mathrm{a}$ \\
\hline Complete List of Authors: & $\begin{array}{l}\text { Richard, Pascale; Hopital Universitaire Pitie Salpetriere, UF Cardiogénétique } \\
\text { et Myogénétique moléculaire et cellulaire } \\
\text { Ader, Flavie; Hopital Universitaire Pitie Salpetriere, UF Cardiogenetic and } \\
\text { Myogenetic; } \\
\text { Roux, Maguelone ; Sorbonne Universités, UPMC Unive., INSERM UMR_S } \\
1166 \\
\text { Donal, Erwan; CHRU Pontchaillou, Service de Cardiologie } \\
\text { Eicher, Jean; Service de Cardiologie, CHU DIJON } \\
\text { Aoutil, Nadia; Hopitaux Universitaires de la Pitié Salpêtrière Charles Foix, } \\
\text { UF Cardiogenetics } \\
\text { Huttin, Olivier; CHRU Nancy, Service de Cardiologie } \\
\text { Selton-Suty, Christine; Chu nancy - hopitaux de brabois, Cardiology } \\
\text { COISNE, Damien; Centre Hospitalier Universitaire de Poitiers, Cardiologie } \\
\text { JONDEAU, Guillaume; Hopital Bichat - Claude-Bernard, Cardiologie } \\
\text { DAMY, Thibaud; Hopital Henri Mondor, Cardiology } \\
\text { MANSENCAL, Nicolas; Hopital Ambroise-Pare, Cardiology } \\
\text { CASALTA, Anne Claire; Hopital de la Timone, Cardiology } \\
\text { MICHEL, Nicolas; Hopital de la Timone, Cardiology } \\
\text { HAENTJENS, Julie; Hopital de la Timone, Cardiology } \\
\text { Faivre, Laurence; Hopital d'Enfants, Centre de Génétique } \\
\text { LAVOUTE, Cécile; Hopital de la Timone, Cardiology } \\
\text { Nguyen, Karine; APHM, medical genetics } \\
\text { Tregouet, David; INSERM, UMR_S 1166; ICAN Institute, } \\
\text { HABIB, Gilbert; Timone Hospital, Marseille, Cardiology Department, } \\
\text { CHARRON, Philippe; Hopital Universitaire Pitie Salpetriere, Centre de } \\
\text { référence des maladies cardiaques héréditaires }\end{array}$ \\
\hline Key Words: & $\begin{array}{l}\text { Left ventricular non compaction, cardiomyopathy, molecular genetic, next } \\
\text { generation sequencing }\end{array}$ \\
\hline
\end{tabular}


2

3

4

5

6

7

8

10

11

12

13

14

15

16

17

18

19

20

2

22

23

24
25

26

27

28

29

30

32

33

34

35

36

37

43

44

45

46

47

48

49

50

51

52

53

54

55

56

57

58

59

60 


\section{Targeted panel sequencing in adult patients with left ventricular non-compaction reveals a large genetic heterogeneity}

\section{Running title: Genetic complexity of adult left ventricle non compaction}

Pascale Richard ${ }^{1,2}$, Flavie Ader ${ }^{1}$, Maguelonne Roux ${ }^{2}$, Erwan Donal ${ }^{3}$, Jean-Christophe Eicher $^{4}$, Nadia Aoutil ${ }^{1}$, Olivier Huttin ${ }^{5}$, Christine Selton-Suty ${ }^{5}$, Damien Coisne ${ }^{6}$, Guillaume Jondeau $^{7}$, Thibaud Damy $^{8}$, Nicolas Mansencal ${ }^{9}$, Anne-Claire Casalta ${ }^{10}$, Nicolas Michel ${ }^{10}$, Julie Haentjens ${ }^{10}$, Laurence Faivre ${ }^{11}$, Cecile Lavoute ${ }^{10}$, Karine Nguyen $^{12}$, David-Alexandre Tregouët ${ }^{2}$, Gilbert Habib ${ }^{10,13^{*}}$, Philippe Charron ${ }^{2,14,15^{*}}$.

Conflict of interest statement: none declared for each author

1- APHP, UF Cardiogénétique et Myogénétique, Service de Biochimie Métabolique, Hôpitaux Universitaires de la Pitié- Salpêtrière- Charles Foix, 47-83 Bd de l'Hôpital, Paris

2- Sorbonne Universités, UPMC Univ. Paris 06, INSERM, UMR_S 1166 and ICAN Institute for Cardiometabolism and Nutrition, Paris

3- Service de cardiologie, Centre Hospitalier Régional Universitaire Pontchaillou, 2, Rue Henri le Guilloux 35000 Rennes

4- Service de cardiologie, CHU Dijon Bourgogne - Hôpital François Mitterrand, 2 bd Maréchal de Lattre de Tassigny, 21000 DIJON

5- Service de cardiologie, CHU de Nancy, Hôpitaux de Brabois, rue du Morvan, 54500 Vandœuvre-lès-Nancy

6- Service de cardiologie, CHU de Poitiers, 2, Rue de la Milétrie, 86000 Poitiers

7- APHP, Service cardiologie, CHU Paris Nord-Val de Seine - Hôpital Xavier Bichat-Claude Bernard, 46 rue Henri Huchard, 75018 Paris

8- APHP, Service cardiologie, CHU Henri Mondor, 51 Avenue du Maréchal de Lattre de Tassigny, 94010 Créteil 
9- APHP, Service de Cardiologie, CHU Ambroise Paré, 9 av Charles de Gaulle, 92100 Boulogne Billancourt

10- APHM, La Timone Hospital, Cardiology Department, Marseille

11- Service de génétique, CHU Dijon Bourgogne - Hôpital François Mitterrand, 2 bd Maréchal de Lattre de Tassigny, 21000 DIJON

12- APHM, Département de génétique médicale - APHM, La Timone Hospital, INSERM UMR_S 910, Marseille

13- Aix Marseille Univ, IRD, APHM, MEPHI, IHU-Méditerranée Infection, Marseille, France

14- APHP, Centre de référence pour les maladies cardiaques héréditaires, Hôpital PitiéSalpêtrière, Paris

15- Université de Versailles Saint Quentin, Service de Génétique, Hôpital Ambroise Paré, Boulogne-Billancourt

*equal last author

CONFLIT OF INTEREST: None declared for any co-authors.

\section{ACKNOWLEDGMENTS}

Lab team and clinical investigators are warmly acknowledged for the technical realization of this project.

This technical steps and salary of Nadia Aoutil were supported by funds from AP-HM (PHRC 2011-A - 00987-34, coordinator Pr. G. Habib, Marseille). Genetic Labs and sequencing platform was located at APHP, Pitié Salpêtrière Hospital. M. Roux was financially supported by the Fondation pour la Recherche Médicale and the GENMED Laboratory of Excellence on Medical Genomics (ANR-10-LABX-0013). The project was also supported by BestAgeing FP7 European Community project; Leducq Transatlantic Network: "Genomic, epigenomic 
and systems dissection of mechanisms underlying dilated cardiomyopathy"; PROMEX stiftung fur die forschung Charitable Foundation

\begin{abstract}
Left ventricular non-compaction (LVNC) is a cardiomyopathy that may be of genetic origin, however few data are available about the yield of mutation, the spectrum of genes and allelic variations. The aim of this study was to better characterize the genetic spectrum of isolated LVNC in a prospective cohort of 95 unrelated adult patients through the molecular investigation of 107 genes involved in cardiomyopathies and arrhythmias.

Fifty-two pathogenic or probably pathogenic variants were identified in 40 patients $(42 \%)$ including 31 patients $(32.5 \%)$ with single variant and 9 patients with complex genotypes (9.5\%). Mutated patients tended to have younger age at diagnosis than patients with no identified mutation. The most prevalent genes were TTN, then HCN4, MYH7, and RYR2. The distribution includes 13 genes previously reported in LVNC and 10 additional candidate genes.
\end{abstract}

Our results show that LVNC is basically a genetic disease and support genetic counseling and cardiac screening in relatives. There is a large genetic heterogeneity, with predominant TTN null mutations and frequent complex genotypes. The gene spectrum is close to the one observed in dilated cardiomyopathy but with specific genes such as HCN4. We also identified new candidate genes that could be involved in this sub-phenotype of cardiomyopathy.

KEY WORDS: Left ventricular non compaction, cardiomyopathy, molecular genetic, next generation sequencing 


\section{INTRODUCTION}

Left ventricular non-compaction (LVNC, OMIM300183) is a relatively rare cardiomyopathy, with or without LV dysfunction, characterized by excessively prominent trabeculations and associated deep recesses that communicate with the ventricular cavity ${ }^{1}$. LVNC is part of unclassified cardiomyopathies according to the European Society of Cardiology ${ }^{2}$ and to genetic cardiomyopathies by the America Heart Association ${ }^{3}$.

The prevalence of LVNC was estimated at $0.014 \%$ to $1.3 \%$ depending on the age of patients $^{4,5}$. Multiple imaging techniques are usually useful for the diagnosis of LVNC, with variable echocardiographic or magnetic resonance imaging diagnostic criteria but no clear consensus so that the positive diagnosis may be challenging ${ }^{6}$. The phenotypic expression and evolution of isolated LVNC is highly variable, and clinical features can range from asymptomatic to symptomatic, with a relatively stable course over several years or an evolution towards severe complications including congestive heart failure, ventricular arrhythmia and sudden cardiac death, atrial arrhythmias and systemic embolic events ${ }^{6}$.

LVNC is supposed to be related to a premature arrest of compaction of the loose myocardial meshwork during fetal embryogenesis, with persistent trabeculated myocardium, but the precise pathophysiology remains poorly understood. A family history is noticed in a significant proportion of patients and predominant mode of inheritance is autosomal dominant, with some cases with an X-linked transmission ${ }^{7}$.

Several genes have been identified as LVNC disease causing. The first reported genetic cause of isolated LVNC was described by Bleyl et al. with mutations in the X-linked TAZ gene, also responsible for Barth syndrome ${ }^{8}$. The sarcomere-encoding genes ( $M Y H 7$, ACTC1, TNNT2, MYBPC3, TMP1, and TNNI3) appear to account for 17 to $30 \%$ of LVNC 9,10 but other genes such as DTNA (a-dystrobrevin), NKX-2.5, Z-line protein-encoding ZASP/LDB3, lamin A/C (LMNA) genes have been also associated with LVNC ${ }^{11}$. Recently, the TTN gene was also reported as involved in this disease ${ }^{12-14}$, with a highly heterogeneous 
prevalence, as high as $19 \%$ and the first responsible gene for LVNC in a German study of 68 index cases $^{13}$ to $7 \%$ in adults but $0 \%$ in children from a Dutch cohort of 327 patients ${ }^{14}$.

Several studies have analyzed the spectrum of genes in $\mathrm{LVNC}^{9-16}$ but with heterogeneous strategies (Sanger or Next-generation sequencing), usually in retrospective cohorts without imaging core-lab, and usually with a relatively small panel of genes (45 genes in the Dutch study $^{14}$, exome sequencing in the recent German study ${ }^{13}$. Therefore, the exact spectrum of LVNC-causing variants, their prevalence and their impact in genetic counseling remain poorly understood. Furthermore, the unique specificity of LVNC as an independent nosology entity has been questioned and LVNC has been suggested as an overlapping phenotype with hypertrophic or dilated cardiomyopathy ${ }^{9}$. To explore these issues, a prospective French national research program was launched and focused on consecutive adult patients with a recent diagnosis of isolated LVNC. The general aim was to better characterize the allelic and genetic spectrum of LVNC through a large panel of genes previously reported in the various cardiac hereditary diseases. The objective was also to identify new potential candidate genes that could be involved in the phenotype of LVNC.

\section{METHODS}

The present study was conducted as part of the Programme Hospitalier de Recherche Clinique (PHRC Ref: 2011-A - 00987-34, coordinator Pr. G. Habib, Marseille) aimed at describing the clinical spectrum of LVNC and at characterizing the genetic spectrum of LVNC through a next-generation sequencing (NGS) strategy in a new prospective cohort.

\section{Patients, inclusion criteria}

The study included unrelated patients with a minimal age at inclusion of 18 years old, enrolled between 2012 and 2013 in 13 French centers for inherited cardiac diseases. Collected data included clinical data (initial presentation, first symptoms, and data from cardiac and neurologic examination), family history, and tests including ECG, echocardiography, MRI, CT scan, Holter monitoring when available, as well as follow-up 
data. Only patients with a recent diagnosis of isolated LVNC (maximum in the last 6 months before inclusion) were enrolled. All echocardiographic documents were sent and reviewed by a core lab (Marseille) to confirm the diagnosis. Diagnosis of isolated LVNC was considered definite when several criteria were present in left ventricle (LV): (i) multiple trabeculations with deep endomyocardial recesses, (ii) two-layer myocardial structure with a thin compacted (C) and a thick non compacted (NC) layer, (iii) color Doppler evidence of perfused intertrabecular recesses, (iv) systolic NC / C ratio > 2 (parasternal short-axis view); (v) no associated heart disease $^{17}$. Cardiac MRI was also frequently performed in our series, with a NC/C ratio of $>2.3$ in diastole as the recommended threshold for the diagnosis of LVNC using this technique ${ }^{18}$. However, for the purpose of the current study, only the echocardiographic criteria were used as inclusion criteria. Only patients with a diagnosis validated by an imaging core lab confirming a definite diagnosis of LVNC were included. Informed consent, blood samples, and clinical evaluations were obtained from all patients, with a protocol approved by the Ethics Committee of AP-HM (Assistance Publique- Hôpitaux de Marseille).

\section{Genetic analysis}

Targeted gene enrichment, high-throughput sequencing: Patients' DNAs were extracted from peripheral blood with QIAsymphony $®$ (Qiagen, Hilden, Germany) and qualitatively checked using Tape Station DNA genomic array (Agilent, Santa Clara, USA). Custom targeted gene enrichment and DNA library preparation were performed using the Nimblegen EZ choice probes $®$ and Kappa HTP Library preparation kit $®$ according to the manufacturer's instructions (Nimblegen $®$, Roche Diagnostics, Madison, USA). The targeted regions include all coding exons and +/- 50 base pairs of flanking intronic regions of 107 genes known to be involved in cardiomyopathies (77 genes) and arrhythmias (30 genes) (Suppl. Table 1). The targeted regions were sequenced using the Illumina MiSeq platform on a 500 cycle Flow Cell (Illumina, Santa Cruz, USA) and MiSeq Software generates FASTQ format files after demultiplexing patients' sequences. 
Bioinformatics pipeline: In presence of overlapping paired-end reads, these were merged with Flash $^{19}$. Merged single reads and paired-end reads were then aligned on Hg19 human reference genome using BWA-MEM ${ }^{20}$. This was further followed by a local realignment around insertion and/or deletions and a quality base recalibration by using of the GATK program $^{21}$. PCR and optical duplicates were highlighted with the MarkDuplicates Picard tool (http://broadinstitute.github.io/picard) and were further removed using samtools ${ }^{22}$. Resulting .bam outputs from merged single reads and properly paired-end reads were then combined into a unique .bam file. Variant calling was performed using the GATK Haplotype Caller program $^{21}$ simultaneously on all sequenced samples. Detected variants were then annotated using ANNOVAR ${ }^{23}$ and CADD $^{24}$ tools. Coverage statistics were produced using the HsMetrics Picard tool. Detected variants with sequencing depth greater than $30 \mathrm{X}$ and with at least $20 \%$ of reads supporting the alternative allele were kept for analysis. Detection of copy number variation $(\mathrm{CNV})$ was performed after coverage normalization, by computing the ratio of a target's coverage of a given individual over the mean coverage of this target across all patients of the same sequencing run.

Variants interpretation: Pathogenicity of variants was determined according to current ACMG guidelines $^{25}$ that recommend classifying variants into 5 categories: pathogenic, likely pathogenic, unknown significance, likely benign and benign. A recent publication dedicated to cardiomyopathies recommended the use of a frequency threshold of $0.01 \%{ }^{26}$. Variants were filtered out according to their allele frequency as reported in the GnomAD database (http://gnomad.broadinstitute.org/). We then evaluated each variant considering a careful review of the literature, the location of the variant in the gene and the resulting corresponding protein, the in silico prediction tools (Polyphen2, SIFT, GVGD and Mutation Taster for

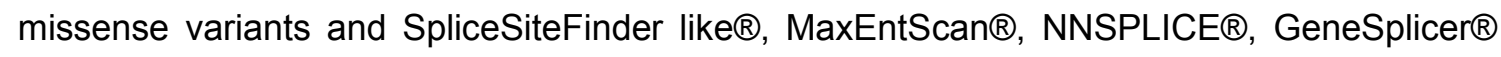
and Human Splicing Finder ${ }^{\circledR}$ for splicing variants) and functional studies when available. Additionally, we looked at a local database of pathogenic variants related to our experience on the molecular diagnosis of cardiomyopathies. In practice, we considered as "pathogenic" 
(class 5), a variant with confirmed pathogenicity criteria and already proved as responsible for cardiomyopathies or a novel nonsense variant with a frequency below $0.01 \%$. We considered as "likely pathogenic" (class 4), unpublished variants with a frequency below $0.01 \%$ and unknown in our database, located in a functional domain of the protein and with pathogenicity prediction tools mainly (at least 3 out of 4 tools) in favor to a strong effect.

"Variants of unknown significance" were new variants with no evidence for predicted deleteriousness and published variants with a frequency over $0.01 \%$. Such variants were not considered in this work until proof of pathogenicity but are presented in supplemental data (Suppl. Table 2). In TTN gene, only null variants (consensus splice sites, stop codons, insertions and deletions leading to a shift in the reading frame) were considered as pathogenic according to a recent publication on TTN mutations in cardiomyopathies ${ }^{27}$, and we excluded other variants, especially TTN missense variants.

All variants considered as pathogenic and probably pathogenic have been confirmed by a second independent method (Sanger sequencing or MLPA)

Statistical analyses were performed with Fisher Exact test or chi2, for binary variables and Student $\mathrm{t}$ tests for continuous variables, when appropriate.

\section{RESULTS}

\section{Patients}

Ninety-five unrelated patients ranging from 19 to 81 years-old were included in the study with a mean age at diagnosis/inclusion of $46.3( \pm 15)$ years old. This cohort was composed of 56 males and 39 females. At the time of inclusion, 46 patients had a NYHA score $>1$, mean ejection fraction at inclusion was $42.5 \%( \pm 14.5)$ and mean heart rate was $68.5 \mathrm{bpm}( \pm 15.6)$.

\section{Performance of the custom panel}

The Miseq sequencing run yielded an output of 1.8 to $2.2 \mathrm{~Gb}$ per sample, with a mean sequencing depth per sample of 265 reads (SD:35.3). On average, 99.7\% of selected targets (1740/1745) were covered over $30 \mathrm{X}$ and $98.5 \%$ (1720/1745) over more than 100X. 


\section{Allelic Spectrum}

Cohort analysis led to the identification of 52 confirmed or highly suspected pathogenic variants (class 5 or 4 ) including 42 novel ones located in 23 different genes. Among these mutations, 50 were found in 22 cardiomyopathies related genes (ACTC1, BAG3, DSC2, DSP, FLNC, HCN4, HEY2, LDB3, LMNA, MYBPC3, MYH6, MYH7, MYLK2, MYPN, NEXN, NKX2.5, PDLIM3, PKP2, RBM20, RYR2, TMEM43 and TTN) and 2 were observed in ANK2 gene, known to be responsible for long QT Syndrome (Table 1).

Among the 22 cardiomyopathy genes, the most prevalent ones were $\operatorname{TTN}$ (19\%, 10 variants), followed by HCN4 and MYH7 genes (10\%, 5 variants each), followed by RYR2 (8\%, 4 variants) then MYH6 and ACTC1 (6\%, 3 variants each), then MYBPC3, LDB3, MYLK2 and $\operatorname{NEXN~(4\% ,~} 2$ variants). The 12 other genes were found mutated only once. Among the arrhythmias genes, ANK2 was mutated in 2 patients (4\%, 2 variants) (Fig. 1).

The 10 TTN truncating variants included 8 variants located in the A-band $(80 \%)$ and two located at the end of the I-band at the junction with A-band. In the 22 remaining genes, 42 mutations were identified including 35 missense variants, 1 in-frame deletion, 5 null mutations (3 frame shifts, 1 splice and 1 non-sense mutations), and a CNV consisting in a complete deletion of RYR2 exon 3 (Table 2).

In the second prevalent gene HCN4, 5 different missense variants were found including one already published in LVNC. These variants were located in transmembrane domain 4 (c.1123C>T, p.Arg375Cys), in the pore (c.1403C>T, p.Ala468Val, c.1438G>T, p.Gly480Cys and c.1444G>A, p.Gly482Arg) before the transmembrane domain 5 (c.1231C>G, p.Leu411Val). (Table 2)

In order to classify genes and variants according to their function in the cardiomyocytes, we defined 5 cellular "compartments" (Fig.1). The distribution of the 52 variants in the 23 genes showed that $52 \%$ of variants $(\mathrm{N}=27)$ were located in sarcomeric genes, $21 \%(\mathrm{~N}=11)$ were in ion channel or related genes, $8 \%(\mathrm{~N}=4)$ were in genes involved in the cellular structure, $6 \%$ 
$(\mathrm{N}=3)$ were located in desmosome genes. In addition, $12 \%$ of variants $(\mathrm{N}=6)$ were found in transcription factors genes or genes involved in other structures or functions (eg. NKX2-5).

Finally, upon the 52 identified variants, 40 were located in the 13 already known LVNC genes $(77 \%)$ and 12 were located in the 10 additional candidate genes (23\%)(Tables $1 \& 2)$.

\section{Multiple mutations in patients}

In the cohort, 9 patients (9.5\%) presented a complex genotype feature with the presence of more than one pathogenic variant. Seven patients harbored two disease-causing variants in cardiomyopathy genes (Fig.2) and 2 patients carried at least 3 pathogenic variants: one with BAG3, MYH7, and NKX2-5 variants and the second with ACTC1, ANK2, LDB3 and MYLK2. Regarding the TTN gene, 8 patients were carrying a unique TTN variant and 2 patients carried a TTN mutation associated with another gene variant (MYH6, NEXN).

\section{Mutations, patients and phenotype}

According to our variant selection criteria, a pathogenic variant was identified in 40 patients of the cohort (20 males and 20 females; $50 \%$ ), including 31 patients $(32.5 \%)$ with single variant and 9 patients with complex genotypes (9.5\%). TTN mutations are predominant and identified in 10 patients of the cohort (10.5\%). In 55 patients (58\%), no genetic cause was identified. Fifteen patients had a known family history of LVNC, 55 patients were sporadic cases and family history was not available for 25 patients. Among these groups, the mutation rate is $53 \%, 46 \%$ and $28 \%$ respectively. The difference between familial cases and sporadic cases is not significant ( $p$-value : 0.77 ).

An analysis was performed regarding the age at diagnosis, ejection fraction, presence of dyspnea $(\mathrm{NYHA}>1)$ and heart rate comparing the groups of mutated patients vs patients with no identified genetic cause. Mutated patients tended to be younger at diagnosis (43.0 vs 48.7 years, $p=0.07$ ) but systolic dysfunction showed no significative difference between groups 
(Table 3). Interestingly, the mutation yield was higher in youngest patients $<65$ years old $(38 / 84,45 \%)$ as compared to oldest patients $>65$ years $(2 / 11,18.2 \%, p$-value: 0.11$)$.

Patients with complex genotypes ( $\geq 2$ mutations), as compared to patients with single variants, tended to be younger at diagnosis and to have a decreased ejection fraction although differences were not significant (Table 3). Finally, in patients carrying a single variant, we observed that the LV mean ejection fraction in patient with a mutation in sarcomeric genes $(\mathrm{N}=18)$ was lower than in patients mutated in non-sarcomeric genes $(\mathrm{N}=13)(43.8 \%$ vs $51.6 \%$, p-value: 0.26$)$

\section{DISCUSSION}

We present here the results of the genetic analysis of a cohort of 95 independent patients (index cases) with LVNC in order to evaluate the yield of mutation screening and to assess the allelic and genetic spectrum of the disease. The design of our study has some characteristics that may differ from previous studies since our project was a prospective study performed in newly diagnosed consecutive patients (diagnosis less than six months) with a validation of the cardiac diagnosis by an expert centralized imaging core-lab. This design was conceived to limit potential inclusion bias and strengthen the representativeness of the cohort. We also focused on isolated LVNC, without associated congenital heart defects, in adult patients in order to have a more homogeneous population. Next generation sequencing was performed with a panel of 107 genes involved in cardiomyopathies and some arrhythmias, which represents the most comprehensive genetic analysis published (exome sequencing was performed by Sedagast-Hamedani et al but only selected genes known to be involved in the phenotype were reported) ${ }^{13}$.

When considering pathogenic or likely pathogenic variants, we identified a mutation in $42 \%$ of the patients, which represents a proportion slightly higher than previously reported in this disease $e^{9,10,13,14,16}$, but relatively similar to features observed in other cardiomyopathies ${ }^{28}$. The distribution of genes revealed a high degree of genetic heterogeneity with putative or 
confirmed pathogenic mutations identified in 23 different genes. The distribution includes 13 genes previously published as associated with the phenotype of LVNC (77\% of variants) and 10 additional candidate genes (9 cardiomyopathy and 1 arrhythmia genes) that were never reported before as associated with LVNC (Table 1). Despite the stringent selection criteria of variants, TTN represents the most prevalent gene in the cohort (19\% of variants or $10.5 \%$ of patients) including 8 variants located in the A-band (80\%). As previously observed in patients with DCM, TTN truncating mutations in the A-band region of the protein were over represented $^{27}$.

The following most prevalent genes were $H C N 4$ and $M Y H 7$, followed by MYH6, RYR2 and ACTC1. Considering others published reports ${ }^{13,14}$, some discrepancies were observed in the gene distribution especially regarding TTN, MYH7, HCN4 and LMNA. Differences in distribution may be related in part to the variable characteristics of the cohorts (isolated LVNC or not, age at diagnosis, incident or prevalent cases). We observed a relatively high proportion of patients with HCN4 pathogenic variants as we found 5 different variants, located in S4, S5 and pore domains of the protein (Table 2). Among these patients $3 / 5$ presented bradycardia (one patient was implanted by a pace maker) but no valvular disease has been reported in any of them ${ }^{29,30}$. This suggests that this recently published gene ${ }^{29}$ constitutes an important disease-causing gene in LVNC. The prevalence of HCN4 did not appear as such in previously published cohorts, possibly due to the absence of this gene in some studied panels $s^{9-11,14,15}$ or a difference in the cohort recruitment ${ }^{13,16}$. For other genes, a higher rate of $M Y H 7$ variants and a lower rate of $L M N A$ variants were found in our cohort as compared with the study of Sedaghat-Hamedani et al. ${ }^{13}$ while frequency of TTN and MYBPC3 variants were consistent. In the work of van Waning et al. ${ }^{14}$, the proportion of MYH7 and MYBPC3 in the group of adult patients were consistent with us but a lower rate of TTN variants was observed. In older publications ${ }^{9,10}$ in which only sarcomeric genes were analyzed, the spectrum of genes showed that $M Y H 7$ was the most prevalent gene then TNNT2, TMP1, TNNI3. These last three genes were not found mutated in our cohort, which 
could be due to the fact that our cohort is composed by patients with an adult onset of the disease. Interestingly, our results also strengthen the involvement of recently published genes such as $H C N 4^{29,30}$ and $R Y R 2^{31}$ and help to better estimate their prevalence. As a whole, our finding about the large genetic and allelic spectrum is helpful in refining the genes of interest for routine molecular diagnostic of patients with LVNC.

Additionally, we tried to determine if patients reporting a familial history of LVNC, were more frequently found with a mutation than patients presenting as sporadic cases. The cohort includes 15 familial form and 55 sporadic cases, the 25 remaining patients had no information's about their relatives. Quite the same rate of mutation identification was found in the group of familial forms and sporadic cases (53\% and $46 \%$ respectively, difference not significant)"

Apart from the report of mutations in genes previously associated with LVNC, an important finding of our study is that we identified mutations in 10 genes known to be involved in cardiac inherited diseases but not described until now as associated with this specific phenotype. Among these genes, 9 were previously reported as associated with other sub-types of cardiomyopathy such as HCM, DCM and ARVC (Table 1), suggesting an overlap between the various cardiomyopathies. Among these 10 genes, MYLK2 and NEXN were identified each in 2 patients and 7 genes (BAG3, FLNC, HEY2, MYPN, PDLIM3, TMEM43 and DSC2) were involved each in only one patient. Although these genes could be good candidates for being pathogenic, the definitive role of these genes for causing LVNC will require confirmation in further studies, especially through segregation analyses in families or functional studies. Similarly, in 2 patients with no particular ECG abnormalities, we identified variants in ANK2 gene known to be involved in long QT syndrome. As ANK2 was never reported before in LVNC, cautious is necessary before any conclusion about the causal role of these variants. However, $\mathrm{HCN} 4$ was initially described in channelopathies and then involved in $\operatorname{LVNC}^{29,30}$, with a significant proportion in our cohort, illustrating the fact that a given gene involved in arrhythmias does not preclude the potential role in LVNC. 
Another observation emerging from this study is the high level of patients $(9.5 \%)$ presenting complex genotypes with causative variants in two (or more) different genes. This feature about double mutated patients was not previously described as so high in adult patients with LVNC. In patients with complex genotypes, cumulative effect of variants have been associated with a higher severity of the disease in one study ${ }^{14}$ but was not analyzed in details in most of other studies. The hypothesis of a gene-dose- effect can be suspected as well as in other sub- morphotypes of cardiomyopathies, particularly in $\mathrm{HCM}$. In the present cohort, patients with complex genotypes tended to have a same age at diagnosis (43.1 vs. 43.5 years old) but more symptoms (dyspnea > NYHA1: $67 \%$ vs $53 \%$ ) and a lower ejection fraction (36\% vs. $47 \%)$. However these differences were not statistically significant and must be confirmed in larger cohorts.

The global analysis of the distribution of genes observed in our cohort of adult patients with LVNC also provides useful information regarding the debated issue of whether or not LVNC is an independent nosological entity or a phenotype overlapping with other cardiomyopathy sub-types such as $\mathrm{HCM}$ or $\mathrm{DCM}^{28,32-34}$. The biggest cohorts published so far about HCM patients (including $3267 \mathrm{HCM}$ patients sequenced on 16 genes and 874 patients sequenced on 20 genes) reported sarcomeric genes (especially MYBPC3) as the major genes $^{26,32}$. In patients with DCM, the $T T N$ gene has been consistently reported as the most frequent mutated gene ${ }^{33}$. In a study of $639 \mathrm{DCM}$ patients sequenced on 84 genes, the highest prevalence observed was for TTN (13\%), PKP2, MYBPC3, DSP, RYR2, DSC2 and SCN5A genes ${ }^{34}$. In the present cohort, we observed that the most prevalent genes are TTN, then MYH7, HCN4, MYH6, and RYR2. This distribution, and the fact that TTN is by far the most frequent gene we observed in LVNC, as well as the high level of complex genotypes, suggests that the genetic profile of LVNC patients is relatively similar to patients with DCM but not similar to patients with $\mathrm{HCM}^{26,28,32-37}$. However, the distribution of LVNC patients presents some specific findings, such as the relatively high rate of $\mathrm{HCN} 4$ gene mutations, which favor the possible specific role of some particular genes in this disorder. 
Limitations. Our results were derived from a cohort of adult-onset patients with isolated LVNC. Therefore, results may not be applicable to a pediatric population or a population with syndromic LVNC. Even though probably pathogenic variants completed all the criteria for pathogenicity, we don't provide family segregation and functional analysis for now.

In conclusion, molecular analysis of 107 genes in 95 adult patients with isolated LVNC shows a mutation detection rate of $42 \%$. These data, coming from the most comprehensive study available until now in terms of genes that were analyzed, show that LVNC is basically a genetic disease in most cases, with a large genetic heterogeneity. The global distribution of genes appears quite close to the profile observed in DCM patients, with TTN as the most frequent mutated gene, but with some specific genes such as HCN4. We found $9.5 \%$ of patients presenting a complex genotype with a disease causing variant in two different genes located on different chromosomes. This observation could explain part of intra-familial variable expressivity in case of bi-lineal inheritance, as some relative should be carrier of a single variant with a moderate phenotype. We also described mutations in 10 genes not described until now as associated with LVNC. Although these genes are putative good candidates for causing LVNC, the definitive causal role of these genes in this phenotype will require confirmation in further studies. 


\section{REFERENCES}

1- Towbin JA, Lorts A, Jefferies JL. Left ventricular non-compaction cardiomyopathy. Lancet. 2015;386:813-25.

2- Elliott $P$, Andersson B, Arbustini E, et al. Classification of the cardiomyopathies: $A$ position statement from the European Society Of Cardiology Working Group on Myocardial and Pericardial Diseases. Eur Heart J 2008; 29:270-276.

3- Maron BJ, Towbin JA, Thiene G, et al. American Heart Association; Council on Clinical Cardiology, Heart Failure and Transplantation Committee; Quality of Care and Outcomes Research and Functional Genomics and Translational Biology Interdisciplinary Working Groups; Council on Epidemiology and Prevention. Contemporary definitions and classification of the cardiomyopathies: An American Heart Association Scientific Statement from the Council on Clinical Cardiology, Heart Failure and Transplantation Committee; Quality of Care and Outcomes Research and Functional Genomics and Translational Biology Interdisciplinary Circulation Journal. Circulation 2006;113:1807-1816.

4- Sandhu R, Finkelhor RS, Gunawardena DR, Bahler RC. Prevalence and characteristics of left ventricular non compaction in a community hospital cohort of patients with systolic dysfunction. Echocardiography. 2008;25:8-12.

5- Pignatelli RH, McMahon CJ, Dreyer WJ, et al. Clinical characterization of left ventricular non compaction in children: a relatively common form of cardiomyopathy. Circ J. 2003;108:2672-2678.

6- Habib G, Charron P, Eicher JC, et al; Working Groups 'Heart Failure and Cardiomyopathies' and 'Echocardiography' of the French Society of Cardiology.. Isolated left ventricular non-compaction in adults: clinical and echocardiographic features in 105 patients. Results from a French registry. Eur J Heart Fail 2011; 13:177-85. 
7- Sasse-Klaassen S, Gerull B, Oechslin E, Jenni R, Thierfelder L. Isolated non compaction of the left ventricular myocardium in the adult is an autosomal dominant disorder in the majority of patients. Am J Med Genet A. 2003; 119: 162-167.

8- Bleyl SB, Mumford BR, Thompson V, et al. Lethal non compaction of the left ventricular myocardium is allelic with Barth syndrome. Am J Hum Genet. 1997;61:86872.

9- Klaassen S, Probst S, Oechslin E, et al. Mutations in sarcomere protein genes in left ventricular non compaction. Circulation. 2008;117:2893-2901.

10-Probst S, Oechslin E, Schuler P, et al. Sarcomere gene mutations in isolated left ventricular non compaction cardiomyopathy do not predict clinical phenotype. Circ Cardiovasc Genet. 2011;4:367-74

11- Xing $\mathrm{Y}$, Ichida F, Matsuoka $\mathrm{T}$, et al. Genetic analysis in patients with left ventricular non compaction and evidence for genetic heterogeneity. Mol Genet Metab. 2006; 88:71-7.

12-Hastings R, de Villiers CP, Hooper C, et al. Combination of Whole Genome Sequencing, Linkage, and Functional Studies Implicates a Missense Mutation in Titin as a Cause of Autosomal Dominant Cardiomyopathy With Features of Left Ventricular Non compaction. Circ Cardiovasc Genet. 2016;7 :426-435.

13-Sedaghat-Hamedani F, Haas J, Zhu F, et al. Clinical genetics and outcome of left ventricular non-compaction cardiomyopathy. Eur Heart J. 2017 ;38:3449-3460.

14- van Waning JI, Caliskan K, Hoedemaekers YM, et al. Genetics, Clinical Features, and Long-Term Outcome of Non compaction Cardiomyopathy. J Am Coll Cardiol. 2018 $20 ; 71: 711-722$

15-Tian T, Wang J, Wang $\mathrm{H}$, et al. A low prevalence of sarcomeric gene variants in a Chinese cohort with left ventricular non-compaction. Heart Vessels. 2015; 30:258-64. 
16-Wang C, Hata Y, Hirono K, et al. A Wide and Specific Spectrum of Genetic Variants and Genotype-Phenotype Correlations Revealed by Next-Generation Sequencing in Patients with Left Ventricular Non compaction. J Am Heart Assoc. 2017 Aug 30;6(9).

17-Jenni R, Oechslin E, Schneider J, Attenhofer Jost C, Kaufmann PA. Echocardiographic and pathoanatomical characteristics of isolated left ventricular noncompaction: a step towards classification as a distinct cardiomyopathy. Heart 2001;86:666-67.

18- Petersen SE, Selvanayagam JB, Wiesmann F, et al. Left ventricular non-compaction: insights from cardiovascular magnetic resonance imaging. J Am Coll Cardiol. 2005; 46:101-105.

19-Magoc T. and Salzberg S. FLASH: Fast length adjustment of short reads to improve genome assemblies. Bioinformatics, 2011; 27:21, 2957-63.

20- Li H and Durbin R. Fast and accurate short read alignment with Burrows-Wheeler Transform. Bioinformatics. 2009; 25:1754-60.

21-McKenna A, Hanna M, Banks E, et al. The Genome Analysis Toolkit: a MapReduce framework for analyzing next-generation DNA sequencing data. Genome Research. 2010; 20:1297-303.

22- Li H., Handsaker B, Wysoker A, et al. The Sequence alignment/map (SAM) format and SAMtools. Bioinformatics, 2009; 25: 2078-9.

23- Wang K, Li M, Hakonarson H. ANNOVAR: Functional annotation of genetic variants from next-generation sequencing data. Nucleic Acids Research. 2010; 38:16, e164.

24-Kircher M, Witten DM, Jain P, O'Roak BJ, Cooper GM, Shendure J. A general framework for estimating the relative pathogenicity of human genetic variants. Nature Genetics, 2014; 46: 310-5. 
25-Richards S, Aziz N, Bale S, et al. Standards and guidelines for the interpretation of sequence variants: a joint consensus recommendation of the American College of Medical Genetics and Genomics and the Association for Molecular Pathology. Genet Med. 2015; 17: 405-424.

26-Walsh R, Buchan R, Wilk A, et al. Defining the genetic architecture of hypertrophic cardiomyopathy: re-evaluating the role of non-sarcomeric genes. Eur Heart J. $2017 ; 0: 1-8$

27-Ware JS, Cook SA. Role of titin in cardiomyopathy: from DNA variants to patient stratification. Nat Rev Cardiol. $2018 ; 15: 241-252$

28-Walsh R, Thomson KL, Ware JS, et al. Reassessment of Mendelian gene pathogenicity using 7,855 cardiomyopathy cases and 60,706 reference samples. Genet Med. 2017;19:192-203.

29- Milano A, Vermeer AM, Lodder EM, et al. HCN4 mutations in multiple families with bradycardia and left ventricular non compaction cardiomyopathy. J Am Coll Cardiol 2014;64:745-56.

30-Schweizer PA, Koenen M, Katus HA, Thomas D. A Distinct Cardiomyopathy: HCN4 Syndrome Comprising Myocardial Noncompaction, Bradycardia, Mitral Valve Defects, and Aortic Dilation.J Am Coll Cardiol. 2017;69:1209-1210.

31- Ohno S, Omura M, Kawamura M, et al. Exon 3 deletion of RYR2 encoding cardiac ryanodine receptor is associated with left ventricular non-compaction. Europace. 2014;16:1646-54.

32- Lopes LR, Syrris P, Guttmann OP, et al. Novel genotype-phenotype associations demonstrated by high-throughput sequencing in patients with hypertrophic cardiomyopathy. Heart. 2015;101:294-301.

33-Herman DS, Lam L, Taylor MR, et al. Truncations of titin causing dilated cardiomyopathy. N Engl J Med. 2012;366: 619-28. 
34-Haas J, Frese KS, Peil B, et al. Atlas of the clinical genetics of human dilated cardiomyopathy. Eur Heart J. 2015 May 7;36:1123-35a.

35-Waldmüller S, Schroeder C, Sturm M, et al. Targeted 46-gene and clinical exome sequencing for mutations causing cardiomyopathies. Mol Cell Probes. 2015;29: 30814.

36- Charron P, Elliott P, Gimeno JR, et al. The Cardiomyopathy Registry of the EURObservational Research Programme of the European Society of Cardiology: baseline data and contemporary management of adult patients with cardiomyopathies. Eur Heart J. 2018 Jan 24. [Epub ahead of print]

37-Mademont-Soler I, Mates J, Yotti R, et al. Additional value of screening for minor genes and copy number variants in hypertrophic cardiomyopathy. PLoS One. 2017;12:e0181465.

38-K.R. Egan, J.C. Ralphe, L. Weinhaus, et al. Just sinus bradycardia or something more serious? Case Rep Pediatr, 2013, p. 736164.

39- L. Shan, N. Makita, Y. Xing, et al. SCN5A variants in Japanese patients with left ventricular noncompaction and arrhythmia Mol Genet Metab,2008;93:468-474.

40-Parent JJ, Towbin JA, Jefferies JL. Fibrillin-1 Gene Mutations in Left Ventricular Noncompaction Cardiomyopathy. Pediatr Cardiol. 2016;37:1123-6.

41-Arndt AK, Schafer S, Drenckhahn JD, et al. Fine Mapping of the 1p36 Deletion Syndrome Identifies Mutation of PRDM16 as a Cause of Cardiomyopathy. Am J Hum Genet 93:67-77.

42- Ramond F, Janin A, Filippo SD, et al. Homozygous PKP2 deletion associated with neonatal Left Ventricule Non Compaction. Clin Genet. 2017;91:126-130.

43-Williams T, Machann W, Kühler L, et al. Novel desmoplakin mutation: juvenile biventricular cardiomyopathy with left ventricular non-compaction and acantholytic palmoplantar keratoderma. Clin Res Cardiol. 2011;100 :1087-93. 
Table 1: List of genes published in LVNC cardiomyopathy and potentially new genes identified in the present work.

\begin{tabular}{|c|c|c|c|c|c|}
\hline Cellular structure & Gene (NM) & Protein & Phenotype & Ref. in LVNC & This Cohort \\
\hline \multicolumn{6}{|l|}{ Sarcomere } \\
\hline & MYH7 (NM_000257.2) & Myosin heavy chain & HCM, DMC, LVNC & $9-10$ & yes \\
\hline & TNNT2 (NM_001001430.1) & Troponin T2 & HCM, DMC, LVNC & $9-10$ & no \\
\hline & ACTC1 (NM_005159.4) & Cardiac Actin & HCM, DMC, LVNC & $9-10$ & yes \\
\hline & MYBPC3 (NM_000256.3) & Cardiac C protein & HCM, DMC, LVNC & $9-10$ & yes \\
\hline & TPM1 (NM_001018005.1) & Alpha-tropomyosin & HCM, DMC, LVNC & $9-10$ & no \\
\hline & TNNI3 (NM_000363.4) & Troponin 13 & HCM, DMC, LVNC & $9-10$ & no \\
\hline & DTNA (NM_001390.4) & Alpha-Dystrobrevin & DCM, LVNC & 11-15 & no \\
\hline & MYH6 (NM_002471.3) & Myosin light chain & DCM, HCM, LVNC & 15 & yes \\
\hline & ACTN2 (NM_001103.2) & Actinin & HCM, LVNC & 32 & no \\
\hline & $T T$ (NM_001256850.1) $_{1}$ & Titin & DMC, HCM, LVNC & 12 & yes \\
\hline & MYLK2 (NM_033118.3) & Myosin Light chain kinase & DCM & This work & yes \\
\hline & $M Y P N$ (NM_032578.2) & Myopalladin & DCM & This work & yes \\
\hline & $N E X N$ (NM_144573.3) & Nexilin & HCM, DCM & This work & yes \\
\hline \multicolumn{6}{|l|}{ Structure } \\
\hline & FLNC (NM_001458.4) & Filamin-C & HCM, DCM & This work & yes \\
\hline & LDB3 (NM_007078.2) & LIM Domain Binding 3 & DCM, LVNC & $11-15$ & yes \\
\hline & LMNA (NM_170707.2) & Lamine A/C & DMC, LVNC & 11-15 & yes \\
\hline \multicolumn{6}{|c|}{$\begin{array}{l}\text { lon channel and related } \\
\text { genes }\end{array}$} \\
\hline & ANK2 (NM_001148.4) & Ankyrin 2 & LQT & This work & yes \\
\hline & \multirow[t]{2}{*}{ HCN4 (NM_005477.2) } & $\begin{array}{lllll}\text { Hyperpolarization } & \text { Activated } & \text { Cyclic } & \text { Nucleotide } & \text { Gated }\end{array}$ & ARVC, LVNC & 29,30 & yes \\
\hline & & Potassium Channel 4 & & & \\
\hline & RYR2 (NM_001035.2) & Ryanodin receptor 2 & ARVC, LVNC, CPVT & 31 & yes \\
\hline & CASCQ2 (NM_001232.3) & Calsequestrin 2 & QTL, LVNC & 38 & no \\
\hline & SCN5A (NM_198056.2) & Sodium channel, voltage-gated, type $\mathrm{V}$, alpha subunit & LQT, Brugada, DCM, LVNC & 39 & no \\
\hline
\end{tabular}




\begin{tabular}{|c|c|c|c|c|c|}
\hline Other & & & & & \\
\hline & $N k \times 2.5$ (NM_004387.3) & NK2 Homeobox 5 & DCM, LVNC & 11-15 & yes \\
\hline & TAZ (NM_000116.3) & Taffazin & Barth Syndrom, LVNC & 8 & no \\
\hline & FBN1 (NM_000138.4) & Fibrillin & Marfan Syndrom, LVNC & 40 & no \\
\hline & $A B C C 9_{\left(N M \_020297\right)}$ & ATP Binding Cassette Subfamily C Member 9 & DCM, LVNC & 35 & no \\
\hline & PDRM16 (NM_022114) & PR/SET Domain 16 & LVNC & 41 & no \\
\hline & BAG3 (NM_004281.3) & BCL2 Associated Athanogene 3 & DCM & This work & yes \\
\hline & HEY2 (NM_012259) & Hairy-Related Transcription Factor 2 & DCM & This work & yes \\
\hline & PDLIM3 (NM_014476.4) & PDZ And LIM Domain 3 & ARVC, HCM & This work & yes \\
\hline & RBM20 (NM_001134363.1) & RNA Binding Motif Protein 20 & DCM & 13 & yes \\
\hline & TMEM43 (NM_024334.2) & TransmembraneProtein 43 & ARVC & This work & yes \\
\hline \multicolumn{6}{|c|}{ Desmosome } \\
\hline & PKP2 (NM_004572.3) & Plakophilin 2 & ARVC, LVNC & 42 & yes \\
\hline & $D S P$ (NM_004415.2) & Desmoplakin & ARVC, LVNC, DCM & 43 & yes \\
\hline & DSC2 (NM_024422.3) & Desmocollin & ARVC & This work & yes \\
\hline
\end{tabular}


Table 2: List of pathogenic and probably pathogenic variants identified in the cohort.

Position c., cDNA position; Position p., protein effect; Published: No or Yes; Associated phenotype for published variants; GnomAD correspond to the allelic frequency, and Htz corresponds to the allele count in GnomAD in all populations; GVGD, SIFT, Mutation taster and polyphen are algorythms corresponding to in silico Predictive Algorithms used for evaluation of missense variants. Range of scores for each are indicated in the title column; "Type" indicated the nature of the variant; MS: missense, NS; Nonsense, Del; deletion, Splice; mutation affecting splicing site. Column "interpretation", indicates conclusions about the pathogenicity of the variant: class 5 ; certainly pathogenic, Class 4 ; probably pathogenic. NA: not applicable

\begin{tabular}{|c|c|c|c|c|c|c|c|c|c|c|c|}
\hline Gene & Position c. & Position $p$ & $\begin{array}{c}\text { Published } \\
\text { No/Yes }\end{array}$ & $\begin{array}{l}\begin{array}{l}\text { Associated } \\
\text { phenotype }\end{array} \\
\end{array}$ & GnomAD, Htz & $\begin{array}{c}\text { GVGD } \\
(\mathrm{C} 65-\mathrm{CO}) \\
\end{array}$ & $\begin{array}{l}\text { SIFT } \\
(0-1) \\
\end{array}$ & $\begin{array}{c}\text { Mutation Taster } \\
(1-0)\end{array}$ & $\begin{array}{l}\text { Polyphen } \\
(1-0)\end{array}$ & Type & Interpretation \\
\hline ACTC1 & c. $670 G>T$ & p.Asp224Tyr & N & NA & 1 & 65 & 0 & 1 & 0.994 & MS & Class 4 \\
\hline ACTC1 & $c .281 A>G$ & p.Asn94Ser & $\mathrm{N}$ & NA & $4.061 \mathrm{e}-6,1$ & 45 & 0 & 1 & 0.615 & MS & Class 4 \\
\hline ACTC1 & c. $623 \mathrm{G}>\mathrm{A}$ & p.Arg208His & $\mathrm{N}$ & NA & $4.061 \mathrm{e}-5,10$ & 25 & 0 & 1 & 0,01 & MS & Class 4 \\
\hline ANK2 & c.11150T>A & p.lle3717Asn & $\mathrm{N}$ & NA & $1.083 e-5,3$ & 45 & 0 & 0,995 & 0.865 & MS & Class 4 \\
\hline ANK2 & c. $9145 \mathrm{C}>\mathrm{T}$ & p.Arg3049Trp & $\mathrm{N}$ & NA & $8.155 e-6,2$ & 65 & 0 & 0,93 & 0.999 & MS & Class 4 \\
\hline$B A G 3$ & c.465_466insGCG & p.Ala155delinsAlaAla & $\mathrm{N}$ & NA & 1 & NA & NA & NA & NA & MS & Class 4 \\
\hline DSC2 & c. $1448 \mathrm{~A}>\mathrm{T}$ & p.Asn483lle & $\mathrm{N}$ & NA & I & 15 & 0 & NA & 0.905 & MS & Class 4 \\
\hline$D S P$ & c.3035delA & p.Asp1012fs & $\mathrm{N}$ & NA & I & NA & NA & NA & NA & Del & Class 5 \\
\hline FLNC & c.1933_1935del & p.645del & $\mathrm{N}$ & NA & $3.969 \mathrm{e}-5,11$ & NA & NA & NA & NA & Del & Class 4 \\
\hline HCN4 & c. $1403 C>T$ & p.Ala468Val & $\mathrm{N}$ & NA & $4.065 e-6,1$ & 65 & 0 & 1 & 0,95 & MS & Class 4 \\
\hline HCN4 & c. $1123 C>T$ & p.Arg375Cys & $\mathrm{N}$ & NA & $4.061 \mathrm{e}-6,1$ & 65 & 0 & 1 & 0,99 & MS & Class 4 \\
\hline HCN4 & c. $1231 \mathrm{C}>\mathrm{G}$ & p.Leu411Val & $\mathrm{N}$ & NA & / & 25 & 0 & 1 & 0,99 & MS & Class 4 \\
\hline HCN4 & c. $1444 \mathrm{G}>\mathrm{A}$ & p.Gly482Arg & Y & NCVG & / & 65 & 0 & 1 & 1 & MS & Class 5 \\
\hline HCN4 & c. $1438 \mathrm{G}>\mathrm{T}$ & p.Gly480Cys & $\mathrm{N}$ & NA & I & 65 & 0 & 1 & 1 & MS & Class 4 \\
\hline HEY2 & c. $683 \mathrm{C}>\mathrm{T}$ & p.Thr228Met & $\mathrm{N}$ & NA & $3.231 \mathrm{e}-5,2$ & 0 & 0,05 & 1 & 0,45 & MS & Class 4 \\
\hline LDB3 & c. $625 \mathrm{G}>\mathrm{C}$ & p.Glu209Gln & $\mathrm{N}$ & NA & I & 25 & 0 & 1 & 0,94 & MS & Class 4 \\
\hline LDB3 & c. $608 \mathrm{C}>\mathrm{T}$ & p.Ser203Leu & Y & CMD & $2.538 \mathrm{e}-5,7$ & 65 & 0 & 1 & 0,88 & MS & Class 5 \\
\hline
\end{tabular}




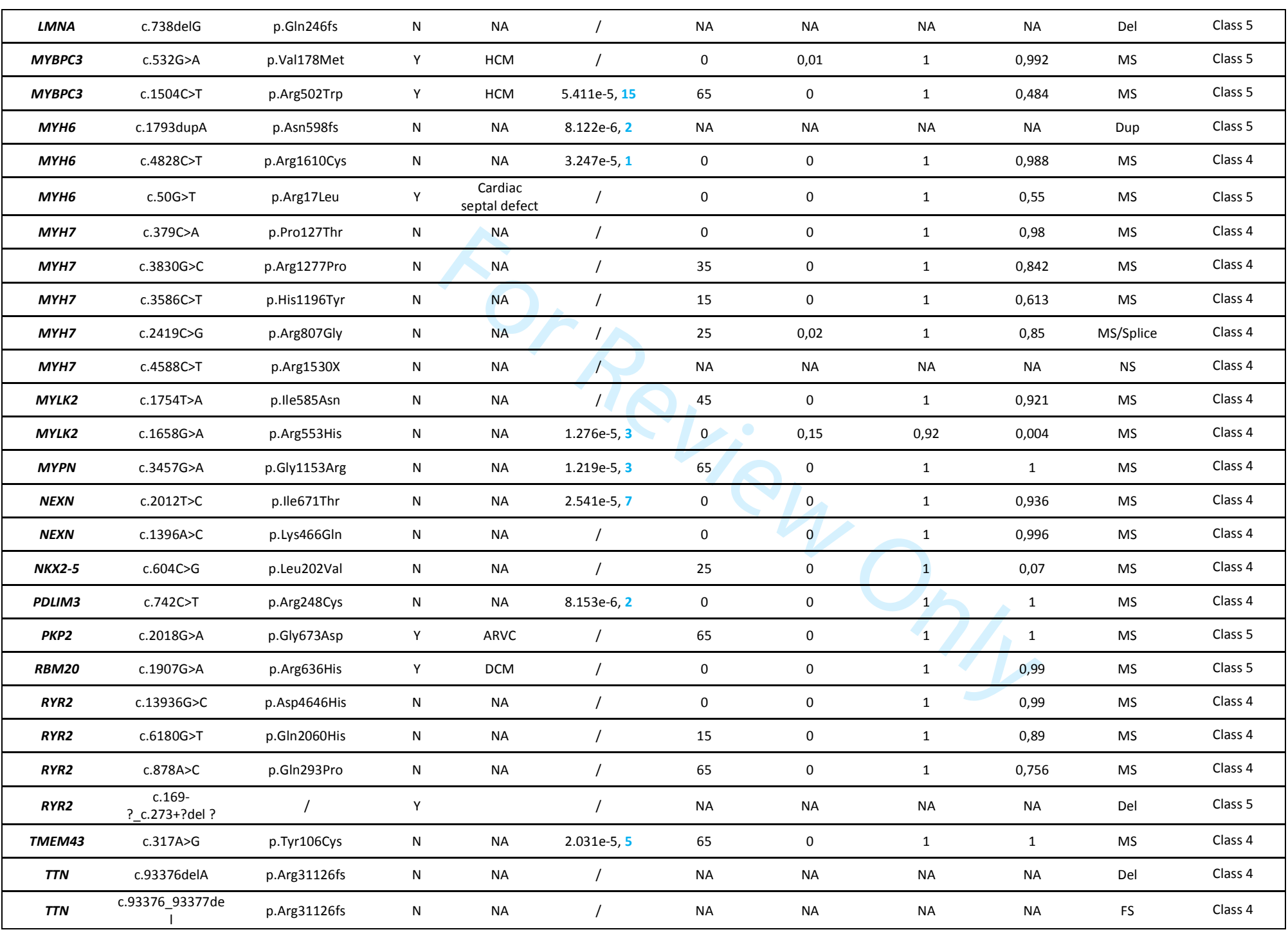




\begin{tabular}{|c|c|c|c|c|c|c|c|c|c|c|c|}
\hline$\pi T N$ & c.82724delA & p.Asn27575fs & N & NA & 1 & NA & NA & NA & NA & FS & Class 4 \\
\hline$T T N$ & $\begin{array}{l}\text { c.98039_98040in } \\
\text { sTCAA }\end{array}$ & p.Asn32680fs & $\mathrm{N}$ & NA & I & NA & NA & NA & NA & Ins & Class 4 \\
\hline$\pi N$ & $\begin{array}{c}\text { c.64100_64101in } \\
\text { sTTGA }\end{array}$ & p.Asp21368X & $\mathrm{N}$ & NA & I & NA & NA & NA & NA & Ins & Class 4 \\
\hline$\pi T N$ & $c .53947 C>T$ & p.Arg17983X & N & NA & l & NA & NA & NA & NA & NS & Class 4 \\
\hline$T T N$ & c.61961G>A & p.Trp20654X & N & NA & I & NA & NA & NA & NA & NS & Class 4 \\
\hline$\pi T N$ & $c .44248 \mathrm{C}>\mathrm{T}$ & p.Arg14750X & $\mathrm{N}$ & NA & I & $\mathrm{NA}$ & NA & NA & NA & NS & Class 4 \\
\hline$\pi T N$ & $c .80845 \mathrm{C}>\mathrm{T}$ & p.Arg26949X & Y & CMD & I & NA & NA & NA & NA & NS & Class 4 \\
\hline$\pi N N$ & c. $43360 \mathrm{C}>\mathrm{T}$ & p.Arg14454x & r & CMD & l & NA & NA & NA & $\mathrm{NA}$ & NS & Class 4 \\
\hline
\end{tabular}


Table 3: Summary of clinical data according to the genetic status

\begin{tabular}{|c|c|c|c|c|c|c|c|c|c|}
\hline & $\begin{array}{l}\text { Mutated } \\
\text { Patients } \\
(\mathrm{N}=40)\end{array}$ & $\begin{array}{l}\text { Not mutated } \\
\text { patients } \\
(\mathrm{N}=55)\end{array}$ & & $\begin{array}{l}\text { Single } \\
\text { mutation } \\
(\mathrm{N}=31)\end{array}$ & $\begin{array}{l}\text { Complex } \\
\text { genotype } \\
(\mathrm{N}=9)\end{array}$ & & $\begin{array}{c}\text { Sarcomeric } \\
\text { gene } \\
(\mathrm{N}=18)\end{array}$ & $\begin{array}{c}\text { Non } \\
\text { Sarcomeric } \\
\text { gene } \\
(\mathrm{N}=13)\end{array}$ & \\
\hline Mean Age (years) & $43.0 \pm 15.5$ & $48.7 \pm 15.2$ & $p=0.07$ & $43.5 \pm 14.5$ & $43.1 \pm 15.3$ & $p=0.94$ & $42.1 \pm 15.7$ & $45.5 \pm 12.9$ & $p=0.78$ \\
\hline NYHA>1 (\%) & 48 & 47 & $p=1.00$ & 41 & 77 & $p=0.12$ & 44 & 31 & $p=0.48$ \\
\hline $\begin{array}{c}\text { Mean Heart rate } \\
(\mathrm{bpm})\end{array}$ & $71 \pm 18$ & $66 \pm 13$ & $p=0.18$ & $70.5 \pm 20$ & $73 \pm 11$ & $p=0.60$ & $72 \pm 17$ & $67 \pm 24$ & $p=0.50$ \\
\hline $\begin{array}{c}\text { Patients with } \\
\text { Ejection Fraction } \\
<50 \%(\%)\end{array}$ & 57 & 71 & $p=0.19$ & 52 & 67 & $p=0.47$ & 61 & 46 & $p=0.48$ \\
\hline
\end{tabular}




\section{FIGURE LEGENDS}

Figure 1: Distribution of genes according to their number of identified pathogenic variants and visualization of their cellular location and function.

Figure 2: Representation of genes association in patients carrying two pathogenic variants. Gene symbol were indicated on the right and left scales. For each of the seven patients carrying 2 mutations, the two mutated genes are connected by a straight line. 


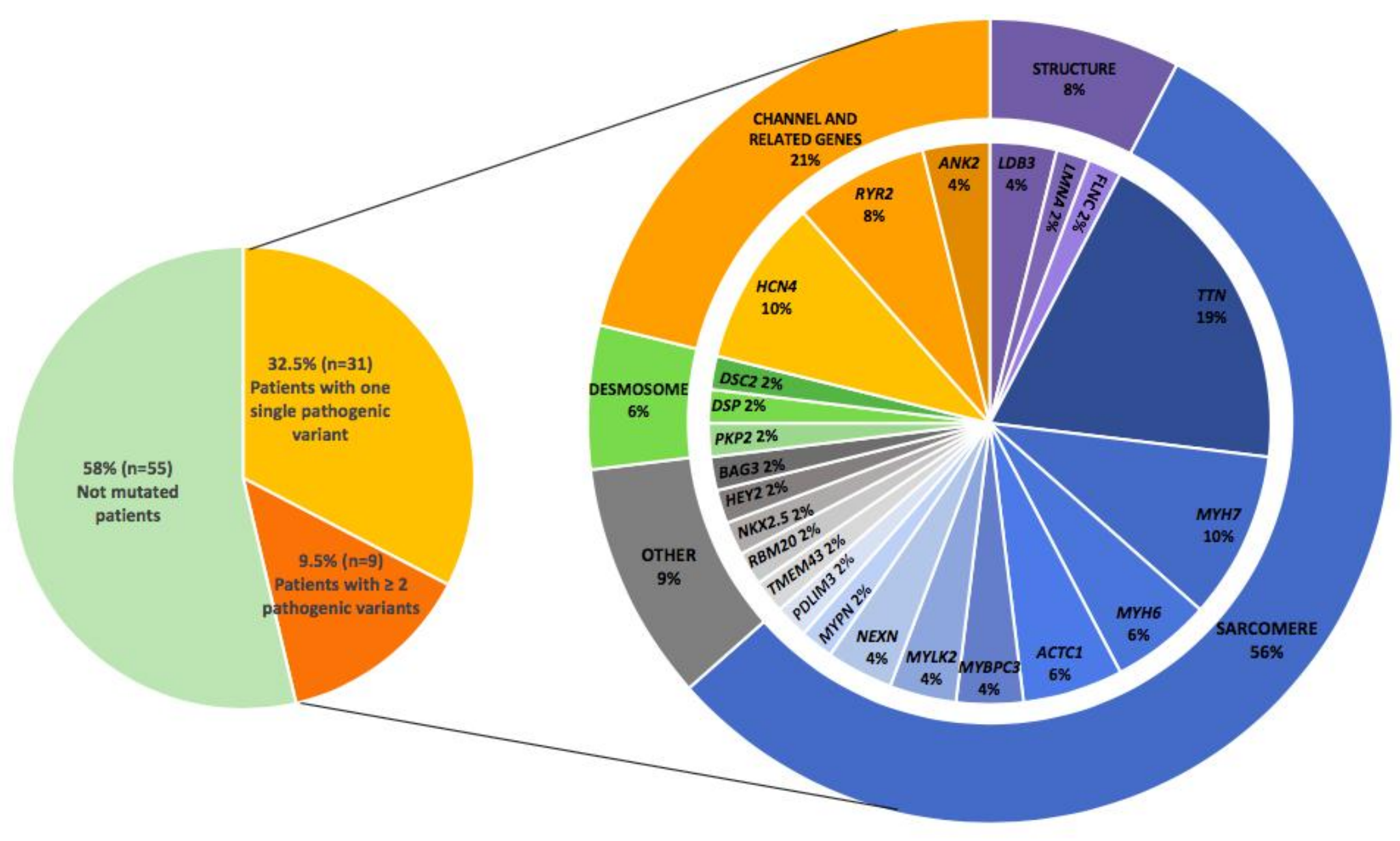




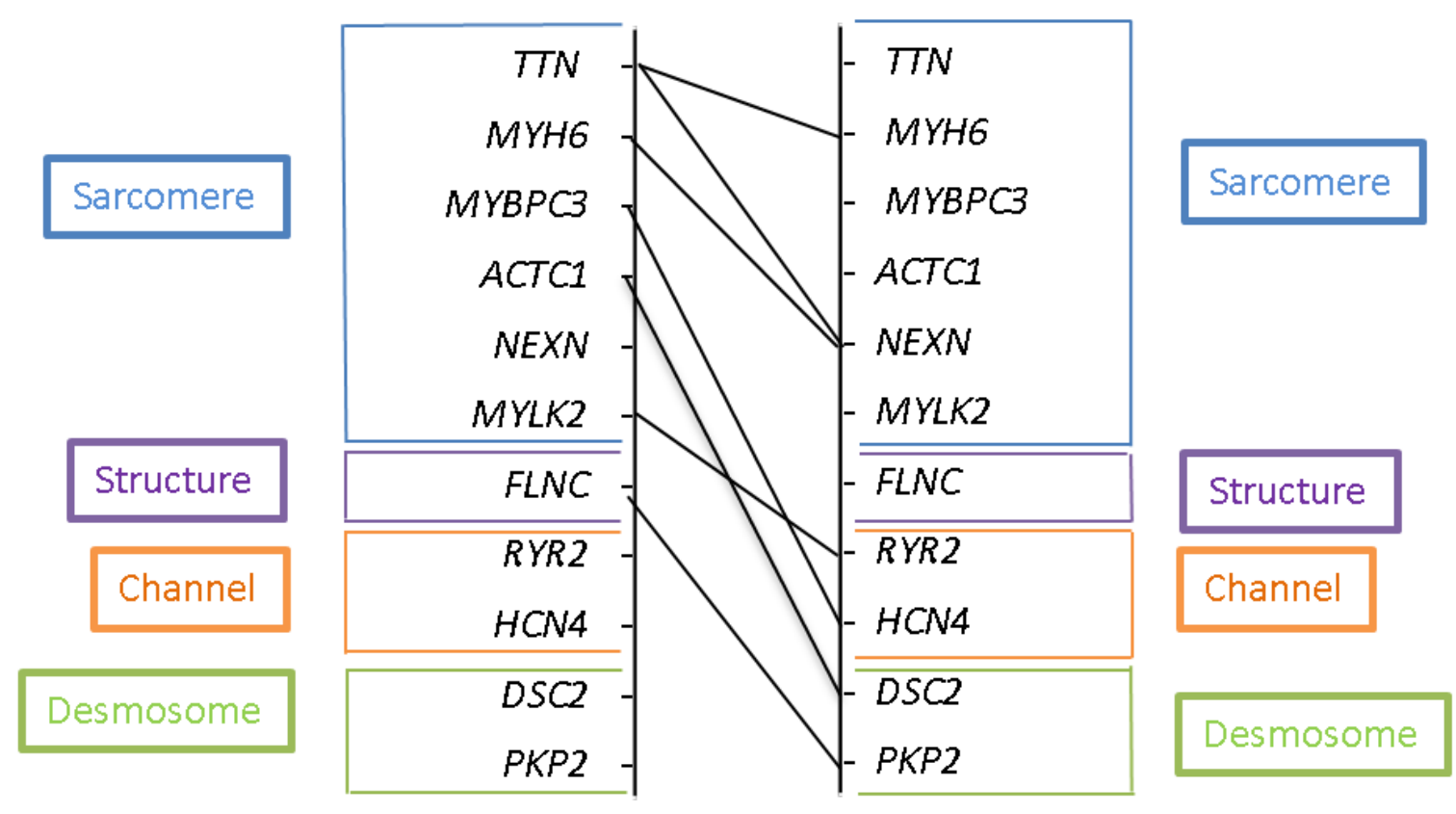


Suppl Data- Table 1: List of genes analyzed in this cohort.

\begin{tabular}{|c|c|c|}
\hline Gene & $\begin{array}{l}\text { Reference } \\
\text { Sequence }\end{array}$ & Chromosome \\
\hline AARS2 & NM_020745.2 & chr6 \\
\hline$A B C C 9$ & NM_020297 & chr12 \\
\hline$A C A D 9$ & NM_014049 & chr3 \\
\hline ACTA1 & NM_001100_ & chr1 \\
\hline ACTC1 & NM_005159.4 & chr15 \\
\hline ACTN2 & NM_001103.2 & chr1 \\
\hline$A G K$ & NM_018238.3 & chr7 \\
\hline AKAP9 & NM_005751.4 & chr7 \\
\hline ANK2 & NM_001148.4 & chr4 \\
\hline$A N K R D 1$ & NM_014391.2 & chr10 \\
\hline BAG3 & NM_004281.3 & chr10 \\
\hline C2orf64(COA5) & NM_001008215.1 & chr2 \\
\hline CACNA1B & NM_000718.2 & chr9 \\
\hline CACNA1C & NM199460.2 & chr12 \\
\hline CACNA2D1 & NM_000722.2 & chr7 \\
\hline CACNB2 & NM_201596.2 & chr10 \\
\hline CALR3 & NM_145046.3 & chr19 \\
\hline CASQ2 & NM_001232.3 & chr1 \\
\hline CAV3 & MN033337.2 & chr3 \\
\hline COX10 & NM_001303.3 & chr17 \\
\hline COX15 & NM_078470.4 & chr10 \\
\hline CSRP3 & NM_003476.3 & chr11 \\
\hline CTNNA3 & NM_013266.2 & chr10 \\
\hline$D E S$ & NM_001927.3 & chr2 \\
\hline DSC2 & NM_024422.3 & chr18 \\
\hline DSG2 & NM_001943.3 & chr18 \\
\hline$D S P$ & NM_004415.2 & chr6 \\
\hline DTNA & NM_001390.4 & chr18 \\
\hline$E M D$ & NM_000117.2 & $\operatorname{chrX}$ \\
\hline EYA4 & NM_004100.4 & chr6 \\
\hline FBN1 & NM_000138.4 & chr15 \\
\hline FHL1 & NM_001159702 & $\operatorname{chr} X$ \\
\hline FLNC & NM_001458.4 & chr7 \\
\hline GAA & NM_000152.3 & chr17 \\
\hline GJA5 & NM_005266.5 & chr1 \\
\hline GLA & NM_000169.2 & chrX \\
\hline GPD1L & MN_015141.3 & chr3 \\
\hline HCN4 & NM_005477.2 & chr15 \\
\hline HEY2 & NM_012259 & chr6 \\
\hline JPH2 & NM_020433.4 & chr20 \\
\hline JUP & NM_002230.2 & chr17 \\
\hline
\end{tabular}




\begin{tabular}{|c|c|c|}
\hline KCNA5 & NM_002234.2 & chr12 \\
\hline KCND3 & NM_004980.4 & chr1 \\
\hline KCNE1 & NM_000219.3 & chr21 \\
\hline KCNE1L & NM_012282.2 & $\operatorname{chr} X$ \\
\hline KCNE2 & NM_172201.1 & chr21 \\
\hline KCNE3 & NM_005472.4 & chr11 \\
\hline KCNH2 & NM000238.2 & chr7 \\
\hline KCNJ2 & NM000891.2 & chr17 \\
\hline KCNJ5 & NM_000890.3 & chr11 \\
\hline KCNJ8 & NM_004982.2 & chr12 \\
\hline KCNQ1 & NM 000218.2 & chr11 \\
\hline KRAS & NM_004985.3 & chr12 \\
\hline LAMP2 & NM_002294.2 & $\operatorname{chr} X$ \\
\hline$\angle D B 3$ & NM_007078.2 & chr10 \\
\hline LMNA & NM_170707.2 & chr1 \\
\hline MRPL44 & NM_022915.3 & chr2 \\
\hline MYBPC3 & NM_000256.3 & chr11 \\
\hline MYH6 & NM_002471.3 & chr14 \\
\hline MYH7 & NM_000257.2 & chr14 \\
\hline MYL2 & NM_000432.3 & chr12 \\
\hline MYL3 & NM_000258.2 & chr3 \\
\hline MYLK2 & NM_033118.3 & chr20 \\
\hline MYOM1 & NM_003803.3 & chr18 \\
\hline MYOZ2 & NM_016599.3 & chr4 \\
\hline MYPN & NM_032578.2 & chr10 \\
\hline$N E B L$ & NM_006393.2 & chr10 \\
\hline NEXN & NM_144573.3 & chr1 \\
\hline$N K X 2-5$ & NM_004387.3 & chr5 \\
\hline NPPA & NM_006172 & chr1 \\
\hline PDLIM3 & NM_014476.4 & chr4 \\
\hline$P K P 2$ & NM_004572.3 & chr12 \\
\hline$P L N$ & NM_002667.3 & chr6 \\
\hline PRDM16 & NM_022114 & chr1 \\
\hline PRKAG2 & NM_016203.3 & chr7 \\
\hline PSEN1 & NM_000021.3 & chr14 \\
\hline PSEN2 & NM_000447.2 & chr1 \\
\hline PTPN11 & NM_002834.3 & chr12 \\
\hline RAF1 & NM_002880.3 & chr3 \\
\hline RANGRF & NM_016492.4 & chr17 \\
\hline RBM20 & NM_001134363.1 & chr10 \\
\hline RYR2 & NM_001035.2 & chr1 \\
\hline SCN1B & NM_199037.3 & chr19 \\
\hline SCN2B & NM_004588.4 & chr11 \\
\hline$S C N 3 B$ & NM018400.3 & chr11 \\
\hline SCN4B & NM174934.3 & chr11 \\
\hline
\end{tabular}




\begin{tabular}{|l|l|l|}
\hline SCN5A & NM_198056.2 & chr3 \\
\hline SCO2 & NM_001169109.1 & chr22 \\
\hline SDHA & NM_004168.2 & chr5 \\
\hline SGCD1 & NM_000337.5 & chr5 \\
\hline SLC25A4 & NM_001151.3 & chr4 \\
\hline ANT1) & NM_003098.2 & chr20 \\
\hline SNTA1 & NM_005633.3 & chr2 \\
\hline SOS1 & NM_133477.2 & chr4 \\
\hline SYNPO2 & NM_000116.3 & chrX \\
\hline TAZ & NM_003673.3 & chr17 \\
\hline TCAP & NM_003239.2 & chr14 \\
\hline TGFB3 & NM_024334.2 & chr3 \\
\hline TMEM43 & NM_017866.5 & chr8 \\
\hline TMEM70 & NM_003276.2 & chr12 \\
\hline TMPO & NM_003280.2 & chr3 \\
\hline TNNC1 & NM_000363.4 & chr19 \\
\hline TNNI3 & NM_001001430.1 & chr1 \\
\hline TNNT2 & NM_001018005.1 & chr15 \\
\hline TPM1 & NM_001256850.1 & chr2 \\
\hline TTN & NM_000371.3 & chr18 \\
\hline TTR & & chr10 \\
\hline VCL & NM000.2 & \\
\hline
\end{tabular}


Suppl. Data- Table 2: list of variants interpreted as VUS found in the cohort.

\begin{tabular}{|c|c|c|}
\hline Gene name & HGVSc. & HGVSp. \\
\hline AARS2 & c. $1752+13 C>T$ & --- \\
\hline AARS2 & $\mathrm{c} .44 \mathrm{C}>\mathrm{G}$ & p.Ala15Gly \\
\hline ABCC9 & c. $2424+10 A>G$ & --- \\
\hline ABCC9 & c. $4212-31 \mathrm{~T}>\mathrm{G}$ & --- \\
\hline ABCC9 & c. $1981 \mathrm{C}>\mathrm{T}$ & p.Arg661Cys \\
\hline ABCC9 & c.1165-7_1165-6delTT & --- \\
\hline ABCC9 & c. $-38 \mathrm{C}>\mathrm{A}$ & --- \\
\hline ACAD9 & c. $244+7 A>G$ & --- \\
\hline ACTN2 & c. $2057 \mathrm{~T}>\mathrm{A}$ & p.lle686Asn \\
\hline AGK & c. $21 \mathrm{G}>\mathrm{A}$ & p.Thr7Thr \\
\hline AKAP9 & c. $11546+11 G>C$ & --- \\
\hline AKAP9 & c. $11229 \mathrm{G}>\mathrm{A}$ & p.Met3743lle \\
\hline AKAP9 & c. $11384 A>G$ & p.Asn3795Ser \\
\hline AKAP9 & c.4246-4G>T & --- \\
\hline AKAP9 & c. $7212 \mathrm{C}>\mathrm{T}$ & p.Thr2404Thr \\
\hline ANK2 & c. $11032+45 \_11032+50$ delGTGTGT & --- \\
\hline ANK2 & c. $1288-40 \mathrm{C}>\mathrm{A}$ & --- \\
\hline ANK2 & c. $2179-11 \mathrm{~A}>\mathrm{G}$ & --- \\
\hline ANK2 & c. $2024 C>G$ & p.Thr675Arg \\
\hline ANK2 & c. $5072 A>G$ & p.GIn1691Arg \\
\hline ANK2 & c. $7915 \mathrm{C}>\mathrm{G}$ & p.His2639Asp \\
\hline ANK2 & c. $2662 C>A$ & p.Arg888Arg \\
\hline ANK2 & c. $4710 \mathrm{C}>\mathrm{T}$ & p.Thr1570Thr \\
\hline ANK2 & c. $7161 \mathrm{~T}>\mathrm{C}$ & p.Ala2387Ala \\
\hline CACNA1B & c.2268-23dupG & --- \\
\hline CACNA1B & c. $3413+22 T>C$ & --- \\
\hline CACNA1B & c. $3711-41 \mathrm{~A}>\mathrm{T}$ & --- \\
\hline CACNA1B & c. $4473+20 \mathrm{G}>\mathrm{C}$ & --- \\
\hline CACNA1B & c. $5777+34 \mathrm{G}>\mathrm{A}$ & $-\cdots$ \\
\hline CACNA1B & c. $274 \mathrm{~A}>\mathrm{G}$ & p.Thr92Ala \\
\hline CACNA1B & c. $282 \mathrm{G}>\mathrm{T}$ & p.Trp94Cys \\
\hline CACNA1B & c. $4497 \mathrm{C}>\mathrm{T}$ & p.Tyr1499Tyr \\
\hline CACNA1B & c. $5052 \mathrm{C}>\mathrm{T}$ & p.Ala1684Ala \\
\hline CACNA1B & c. $6936 \mathrm{C}>\mathrm{T}$ & p.Asn2312Asn \\
\hline CACNA1C & c. $1218-48 \mathrm{C}>\mathrm{T}$ & --- \\
\hline CACNA1C & c.2531-39G $>\mathrm{T}$ & --- \\
\hline CACNA1C & c.5823-16G>A & --- \\
\hline CACNA1C & c.5930-33G $>\mathrm{T}$ & --- \\
\hline CACNA1C & c. $3280 \mathrm{~A}>\mathrm{G}$ & p.lle1094Val \\
\hline CACNA1C & c. $5519 \mathrm{~A}>\mathrm{G}$ & p.Glu1840Gly \\
\hline CACNA1C & c. $2460 \mathrm{G}>\mathrm{C}$ & p.Lys820Asn \\
\hline CACNA2D1 & c.1516-10delT & $-\cdots$ \\
\hline CACNA2D1 & c. $728+29 A>G$ & --- \\
\hline CACNB2 & c.121_122insTTTTTT & p.GIn40_Ser41insPhePhe \\
\hline CACNB2 & c.1302+51_1302+52insCTTTTTTTTTTTT & $-\cdots$ \\
\hline CACNB2 & c.886-36dupT & $-\ldots$ \\
\hline CACNB2 & c. $1550 \mathrm{~A}>\mathrm{C}$ & p.Glu517Ala \\
\hline CACNB2 & c. $1880 \mathrm{G}>\mathrm{A}$ & p.Arg627His \\
\hline CACNB2 & c. $1650 \mathrm{C}>\mathrm{T}$ & p.Ser550Ser \\
\hline CoX15 & c.507C>T & p.Tyr169Tyr \\
\hline CoX15 & c. $876 \mathrm{C}>\mathrm{G}$ & p.Ser292Ser \\
\hline COX15 & c. $999 A>G$ & p.Ser333Ser \\
\hline DES & c. $1245-39 \mathrm{G}>\mathrm{A}$ & --- \\
\hline DES & c. $736-19 \mathrm{G}>\mathrm{A}$ & --- \\
\hline DSC2 & c. $630+45 G>A$ & $-\cdots$ \\
\hline DSC2 & c. $943-27 A>G$ & --- \\
\hline DSC2 & c. $1448 \mathrm{~A}>\mathrm{T}$ & p.Asn483lle \\
\hline DSG2 & c. $1173 \mathrm{C}>\mathrm{A}$ & p.Ser391Arg \\
\hline DTNA & c. $1138 \mathrm{G}>\mathrm{A}$ & p.Ala380Thr \\
\hline DTNA & c. $549 \mathrm{~A}>\mathrm{G}$ & p.Glu183Glu \\
\hline EMD & c. $399+50 \mathrm{C}>\mathrm{T}$ & --- \\
\hline FBN1 & c. $1148-33 G>C$ & --- \\
\hline FBN1 & c. $1571 \mathrm{C}>\mathrm{T}$ & p.Thr524Met \\
\hline FBN1 & c. $3026 \mathrm{C}>\mathrm{T}$ & p.Pro1009Leu \\
\hline FBN1 & c. $165-7 \mathrm{G}>\mathrm{A}$ & --- \\
\hline FBN1 & c. $1530 \mathrm{G}>\mathrm{A}$ & p.Ser510Ser \\
\hline FBN1 & c. $6402 C>T$ & p.Pro2134Pro \\
\hline FLNC & c.1048-11C >T & $-\cdots$ \\
\hline FLNC & c.1210+14delC & --- \\
\hline FLNC & c. $4951+45 \mathrm{~T}>\mathrm{C}$ & --- \\
\hline FLNC & c. $4301 \mathrm{G}>\mathrm{T}$ & p.Arg1434Leu \\
\hline FLNC & c. $7546 \mathrm{G}>\mathrm{A}$ & p.Glu2516Lys \\
\hline FLNC & c. $2733 \mathrm{G}>\mathrm{A}$ & p.Lys911Lys \\
\hline FLNC & c. $492 \mathrm{G}>\mathrm{T}$ & p.Arg164Arg \\
\hline GAA & c. $546+23 C>G$ & --- \\
\hline GAA & c. $2786 G>A$ & p.Ser929Asn \\
\hline GAA & c. $2482-1 \mathrm{G}>\mathrm{T}$ & --- \\
\hline GLA & c. $427 \mathrm{G}>\mathrm{A}$ & p.Ala143Thr \\
\hline GLA & c. $639+31 C>G$ & $-\cdots$ \\
\hline $\mathrm{HCN} 4$ & c. $3081 \mathrm{C}>\mathrm{T}$ & p.Pro1027Pro \\
\hline HEY2 & c. $565 \mathrm{~T}>\mathrm{A}$ & p.Phe189lle \\
\hline HEY2 & c. $438 \mathrm{G}>\mathrm{T}$ & p.Ser146Ser \\
\hline HEY2 & c. $843 C>G$ & p.Ser281Ser \\
\hline JPH2 & c. $1836 \mathrm{C}>\mathrm{A}$ & p.Pro612Pro \\
\hline $\mathrm{JPH} 2$ & C. $1963 C>A$ & p.Arg655Arg \\
\hline KCNA5 & c. $1573 \mathrm{C}>\mathrm{T}$ & p.Arg525Trp \\
\hline KCND3 & c. $1269+18 G>A$ & -- \\
\hline KCND3 & c.1372-6dupT & $-\cdots$ \\
\hline $\mathrm{KCNH} 2$ & c. $431 \mathrm{~A}>\mathrm{T}$ & p.Asp144Val \\
\hline
\end{tabular}


NB: For recessive gene variants were retain only if the patient is carrier of another variant in the same gene, 